REVISTA DE DERECHO UNED, NÚM. 11, 2012

\title{
LA EXIGIBILIDAD DE LOS DERECHOS ECONÓMICOS, SOCIALES Y CULTURALES
}

ENFORCEMENT OF ECONOMIC, SOCIAL AND CULTURAL RIGHTS

\section{CELIa Fernández Aller}

Profesora Universidad Politécnica de Madrid

Titular de Universidad interina. Escuela Universitaria de Informática. Mariacelia.fernandez@upm.es

Resumen: Este texto hace una síntesis de los principales argumentos encontrados en la doctrina y jurisprudencia nacional e internacional que se esgrimen a favor de una mayor exigibilidad de los derechos económicos, sociales y culturales.

Se profundiza en el concepto y fundamento de estos derechos, para a continuación repasar algunos ámbitos de exigibilidad: la Constitución, las normas internacionales, la doctrina y labor de las Instituciones de Derechos Humanos, y las declaraciones de Naciones Unidas.

Para concluir, se aportan ejemplos de algunos tribunales que han entrado a conocer acerca de los derechos DESC.

Abstract: This text is a summary of the main reasons found in the legal doctrine and national and international jurisprudence to justify a greater enforcement of economic, social and cultural rights.

It analyzes the concept of such rights, then go over some areas of enforcement: the Constitution, international standards, doctrine and work of National Human Rights Institutions and UN declarations.

Finally, we provide examples of some courts that have come to know about ESC rights.

Recepción original: 03/10/2012

Aceptación original: 05/10/2012 
Sumario: I. El concepto de exigibilidad; II. Concepto y fundamentación de los derechos económicos, sociales y culturales (DESC); II.1. Determinación de la conducta debida; II.2. La autorrestricción del Poder Judicial frente a cuestiones políticas y técnicas; II.3. La inadecuación de los mecanismos procesales tradicionales para la tutela de derechos sociales; II.4. La escasa tradición de control judicial en la materia; III. La exigibilidad jurídica de los derechos DESC; III.1. En la Constitución Española; III.2. En la legislación internacional de los derechos humanos; III.3. Las instituciones nacionales de defensa de los derechos humanos; III.4. Naciones Unidas; IV. Implicaciones de la exigibilidad jurídica. Algunos ejemplos de jurisprudencia favorable a la exigibilidad de los derechos DESC.

\section{EL CONCEPTO DE EXIGIBILIDAD}

A pesar de que los textos internacionales de derechos humanos acogen la idea de que todos los derechos humanos son indivisibles, interdependientes y de igual importancia, los derechos económicos, sociales y culturales han sido ampliamente descuidados. Uno de los motivos ha sido el argumento de que los derechos económicos, sociales y culturales (en adelante, DESC), no pueden ser examinados ni aplicados por los tribunales. Frecuentemente olvidados y desplazado su cumplimiento hasta un momento posterior que nunca llega -con base en el principio de realización progresiva-, los derechos «DESC» son derechos de difícil reivindicación por parte de los ciudadanos. Hay quien los considera principios y aspiraciones de difícil o dudosa exigibilidad.

Superar la brecha que existe entre los derechos económicos, sociales y culturales y los derechos civiles y políticos en términos de justiciabilidad es una de las condiciones fundamentales para poder asegurar la universalidad de todos los derechos humanos.

El objetivo de este trabajo es profundizar en las vías que existen para conseguir que los derechos económicos, sociales y culturales sean una exigencia de la justicia.

De esta forma, ningún ciudadano en España se plantea exigir su derecho a la vivienda, a la salud, o al agua. Sin embargo, existen constantes y frecuentes violaciones de estos derechos que, según nuestra opinión, podrían ser objeto de exigibilidad. 
Entendemos la exigibilidad como un proceso social, político y le$\mathrm{gal}^{1}$. La forma y medida en que un Estado cumpla con sus obligaciones respecto de los DESC no solamente ha de ser objeto de examen por parte de los órganos judiciales o aquellos encargados de la verificación del cumplimiento de las normas que los consagran y garantizan, sino que debe abarcar la participación activa de la sociedad civil en esta tarea como una condición esencial del ejercicio de su ciudadanía. Esta forma de participación constituiría la exigibilidad social. La exigibilidad política se podría articular a través de incidencia en políticas públicas y programas gubernamentales, impulso a leyes o reforma de leyes, movilizaciones, etcétera.

Habitualmente se entiende exigibilidad desde el punto de vista legal, como exigibilidad jurídica: en ese caso, nos referimos a la llamada justiciabilidad, e implica defensa de derechos violados ante tribunales o instancias administrativas adecuadas.

\section{CONCEPTO Y FUNDAMENTACIÓN DE LOS DERECHOS DESC}

Se ha repetido muchas veces que los DESC - derechos económicos, sociales y culturales, que son los más relacionados con las situaciones de pobreza, como la falta de acceso a la educación, al trabajo, a la vivienda, al agua- no son exigibles. Se ha dicho que los derechos sociales son sólo normas programáticas, que no otorgan derechos subjetivos en el sentido tradicional del término. En otras palabras, se insiste en que los DESC son de aplicación progresiva, deduciendo de ello que no son justiciables, sino que se irán realizando a medida que los recursos de los Estados lo permitan.

Un hecho fuera de toda duda es la aparición de los derechos sociales como variantes del contenido de los derechos fundamentales². Lo que antes eran principios dirigidos a poner límite a la actuación del Estado se han convertido en normas relacionadas con el orden económico y social; más que garantías que defienden la individualidad, son reglas en las que prima el interés colectivo; los derechos sociales tienen la finalidad de asegurar la participación en los recursos sociales a los distintos miembros de la comunidad.

1 ALOP. «ELEMENTOS BÁSICOS PARA LA COMPRENSIÓN DE LOS DERECHOS HUMANOS ECONÓMICOS, SOCIALES Y CULTURALES. Una revisión del contenido esencial de cada derecho y de las obligaciones del Estado, pág. 26.

2 PÉREZ LUÑO. "Los derechos sociales y su significación actual». Los derechos sociales como una existencia de justicia. Cuadernos Democracia y Derechos Humanos. UAH, 2009, pág. 37. 
Los derechos sociales son normas a través de las cuáles el Estado lleva a cabo una función equilibradora y moderadora de las desigualdades sociales. En sentido subjetivo, podrían entenderse como facultades de los individuos y de los grupos a participar de los beneficios de la vida social, lo que se traduce en determinados derechos y prestaciones, directas o indirectas, por parte de los poderes públicos ${ }^{3}$.

Autores muy reconocidos defienden que los derechos económicos, sociales y culturales son justiciables ${ }^{4}$. Para ello, habría que distinguir en un primer momento la justiciabilidad (que se refiere a cuestiones que pueden o deben resolver los tribunales) y las normas de aplicación inmediata (que permiten su aplicación por los tribunales sin más disquisiciones). No existe ningún derecho DESC que no se pueda considerar que posee algunas dimensiones significativas de justiciabilidad. La adopción de una clasificación rígida de los derechos DESC que los sitúe, por definición, fuera del ámbito de los tribunales sería, por tanto, arbitraria e incompatible con el principio de que los dos grupos de derechos son indivisibles e interdependientes. También se reduciría drásticamente la capacidad de los tribunales para proteger los derechos de los grupos más vulnerables y desfavorecidos de la sociedad 5 .

Aunque estos derechos estén situados en el entorno colectivo del hombre, ello no implica que se dirijan a defender sólo intereses colectivos, o que sólo puedan ejercitarse por los grupos. Se trata de defender a individuos concretos en el seno de sus situaciones en la sociedad. Los derechos sociales tratan de satisfacer intereses de individuos, más que de grupos de ellos.

De esta forma, la actividad positiva del Estado que resulta violatoria de los límites negativos impuestos por un derecho DESC resulta cuestionable judicialmente, y verificada dicha vulneración, el

3 MAZZIOTI, M. «Diritti social», Enciclopedia del Diritto, vol. XII, Giuffre, Milán, 1964, pág. 804.

${ }^{4}$ Vid. entre otros, ABRAMOVICH, Víctor y COURTIS, Christian. Los derechos sociales como derechos exigibles. Trotta, Madrid, 2002; ABRAMOVICH, Victor. "Una aproximación al enfoque de derechos en las estrategias y políticas de desarrollo». Revista de la CEPAL 88, abril 2006; vid. asimismo Perfecto ANDRÉS IBÁÑEZ, en «Garantía judicial de los derechos humanos», Claves, núm. 90, marzo 1999, pág. 10-17, citado por Giner de Grado, C. «Derechos humanos, derechos sociales y normas constitucionales» en Documentación Social, n. ${ }^{\circ} 114,1999$, pág. 49.

Vid. el número monográfico sobre el tema: ZAPATERO, V; GARRIDO GÓMEZ, I. (edit.). "Los derechos sociales como una exigencia de la justicia». Cuadernos de Derechos Humanos. Universidad de Alcalá-Defensor del Pueblo-Cátedra Democracia y Derechos Humanos. Madrid, 2009.

5 Tal es la opinión del Comité DESD en su Opinión General n. 9. 
juez decidirá privar de valor jurídico a la acción o a la manifestación de voluntad del Estado viciada, obligándolo a corregir la manera de respetar el derecho afectado.

Por tanto, el argumento que permite que ni jueces instituciones de derechos humanos -como los Ombudsman- velen por el respeto y protección de los derechos económicos, sociales y culturales está en entredicho. En este sentido, y como ya hemos recordado en otras ocasiones $^{6}$, existe una potente corriente doctrinal que defiende que estos derechos sí pueden llevarse ante la justicia e instituciones de derechos humanos.

Analizaremos a continuación los obstáculos que se esgrimen habitualmente en contra de la exigibilidad de los DESC, y los argumentos a favor que se oponen a ellos.

En la práctica, existen obstáculos para hacer plenamente exigibles los derechos sociales establecidos en una Constitución por vía judicial ante el incumplimiento de los poderes obligados primariamente, es decir, los poderes políticos. En el detalle de estos obstáculos iremos viendo los elementos que fundamentan y configuran los derechos DESC.

Algunos de los obstáculos que habitualmente se esgrimen en contra de la exigibilidad judicial de los DESC son los siguientes ${ }^{7}$ :

\section{II.1. La determinación de la conducta debida}

La falta de especificación concreta del contenido de estos derechos permite que nadie reclame el cumplimiento. Cuando una Constitución o un tratado internacional de derechos humanos se refieren al derecho a la salud, derecho a la educación, derecho al trabajo o derecho a la vivienda, resulta difícil saber cuál es la medida exacta de las prestaciones o abstenciones debidas. Sin embargo, la exigencia de un derecho ante los tribunales requiere de la determinación y concreción del incumplimiento, cosa muy difícil en el caso de los derechos sociales.

A este argumento hay que contestar que la determinación del contenido de todo derecho constitucional se ve afectado por el mismo inconveniente, derivado de la falta de concreción con que se redactan las normas jurídicas. ¿Qué significa «propiedad»? ¿Cuál es el

${ }^{6}$ FDEZ. ALLER; NÚÑEZ RIVERO. «El Defensor del Pueblo en Centroamérica. Análisis comparado». Teoría y Realidad constitucional, n. ${ }^{\circ} 26$, 2. $^{\circ}$ sem. 2010, pág. 471.

${ }^{7}$ Abramovich y Courtis exponen esta cuestión extensamente en «Apuntes sobre exigilidad judicial de los derechos sociales. Disponible on line: http://www.juragentium.unifi.it/es/surveys/latina/courtis.htm (consulta: 1 de junio 2010). 
tipo de «expresión» protegida por la prohibición de censura previa? ¿Cuál es el alcance de la noción de «igualdad»? Sin embargo, esta dificultad jamás ha llevado a la afirmación de que los derechos civiles no sean derechos, o no sean exigibles judicialmente, sino más bien a la tarea de especificación de su contenido y límites, a partir de distintos procedimientos de afinamiento de su significado -principalmente, la reglamentación legislativa y administrativa, la jurisprudencia y el desarrollo de la dogmática jurídica.

En el plano internacional, las Observaciones Generales del Comité de Derechos Económicos, Sociales y Culturales constituyen otro ejemplo de esta tarea de especificación del contenido de los derechos establecidos en el Pacto Internacional respectivo. Lo mismo puede decirse del desarrollo de prácticas de exigibilidad de derechos sociales por la vía judicial ante los tribunales nacionales, que detallaremos más adelante. El desarrollo de una dogmática de los derechos sociales, tanto en sede nacional como internacional, constituye una tarea en muchos casos pendiente, que ofrecerá elementos de especificación más detallada del contenido de los derechos sociales.

En otro orden de cosas, los problemas de falta de especificación del contenido de un derecho son típicos de las normas constitucionales o de tratados de derechos humanos, dado que se trata de las normas de mayor nivel de generalidad del orden jurídico. Esto permite mayor flexibilidad y adaptabilidad a instrumentos normativos cuya modificación es normalmente más gravosa que la de la legislación ordinaria, ofrece a los órganos encargados de especificar el contenido de los derechos contenidos en esos instrumentos un margen de elección compatible con la prudencia y necesidad de evaluación de la oportunidad que requiere la toma de cualquier decisión política, y preserva la brevedad y concisión que hacen de estos documentos el catálogo de principios fundamentales del Estado de derecho.

A todo esto hay que añadir el hecho de la determinabilidad fácti$c a$ : en muchos supuestos, pese a que la conducta debida no resulta específicamente reglada por un texto normativo, fácticamente sólo existe uno o un número limitado de cursos de acción determinables para el respeto, garantía o satisfacción del derecho de que se trate. Por ejemplo, en el contexto del derecho a la asistencia sanitaria, en materias vinculadas con el desarrollo de tratamientos médicos, producción de medicamentos o vacunas ante cuadros concretos de enfermedad, la discrecionalidad del Estado para optar entre cursos de acción alternativos resulta claramente limitada. 


\section{II.2. La autorrestricción del Poder Judicial frente a cuestiones políticas y técnicas}

El segundo argumento para evitar la justiciabilidad de los derechos sociales es el criterio sumamente restrictivo que suelen emplear los jueces para evaluar su facultad de invalidar decisiones que pueden calificarse como políticas. Así, cuando la reparación de una violación de derechos sociales importa una acción positiva del Estado que pone en juego recursos presupuestarios, afecta de alguna manera el diseño o la ejecución de políticas públicas, o implica tomar una decisión acerca de qué grupos o sectores sociales serán prioritariamente auxiliados o tutelados por el Estado, los jueces suelen considerar que tales cuestiones son competencia de los órganos políticos.

\section{II.3. La inadecuación de los mecanismos procesales tradicionales para la tutela de derechos sociales}

Otro escollo para la exigibilidad de los derechos sociales es la falta de adecuación de los mecanismos procesales tradicionales para su tutela. Las acciones judiciales tradicionales tipificadas por el ordenamiento jurídico han sido pensadas para la protección de los derechos civiles clásicos.

Algunas dificultades conceptuales que plantea esta discusión tiene directa relación con la estrecha vinculación de la noción tradicional de derecho subjetivo, la noción individual de propiedad y el modelo de Estado liberal. Dado que gran parte de las nociones sustanciales y procesales propias de la formación jurídica continental surgen del marco conceptual determinado por esta vinculación, muchas de las respuestas casi automáticas que se articulan frente a la posible justiciabilidad de los derechos económicos, sociales y culturales insisten en señalar la falta de acciones o garantías procesales concretas que tutelen los derechos sociales. Para verificar las dificultades que genera el marco teórico en el que se fundan las acciones tradicionales para proteger adecuadamente derechos sociales basta señalar algunos ejemplos, como que las sentencias que condenan al Estado a cumplir obligaciones de hacer no cuentan con resguardos procesales suficientes y resultan por ello de dificultosa ejecución. Sin embargo, la inexistencia de instrumentos procesales concretos para remediar la violación de ciertas obligaciones que tienen como fuente derechos económicos, sociales y culturales no significa que no pudiesen crearse. 


\section{II.4. La escasa tradición de control judicial en la materia}

Un obstáculo cultural es la ausencia de tradición de exigencia de estos derechos -en especial en los casos de derechos que se definen fundamentalmente por una prestación, como los derechos a la salud, educación, vivienda, entre otros- a través de mecanismos judiciales. Pese a la existencia de normas de jerarquía constitucional que consagran estos derechos, en la práctica ha habido poca exigibilidad judicial de estos derechos. Se suele relacionar este hecho con una idea muy conservadora del papel del poder judicial.

Si aceptamos que la finalidad del Estado es garantizar la igual libertad de las personas, debe admitirse que el ejercicio efectivo de la libertad puede violarse no sólo por acción, como pretenden Nozick $^{8}$ y otros autores conservadores, sino también por omisión. En ese sentido, al vínculo entre la libertad negativa y la libertad positiva corresponde el vínculo entre los derechos de libertad y los derechos sociales. Los primeros suponen principalmente deberes generales negativos, de abstención, y los segundos, deberes generales positivos, de prestación. Ambos tienen una misma justificación: proteger los bienes primarios, o las necesidades básicas, de los seres humanos.

Ahora bien, para garantizar la concesión de estos derechos sociales en la práctica, el constitucionalismo propone una serie de controles sobre aquellos poderes encargados de prestarlos: el Estado y el mercado.

1. Los poderes públicos son los principales encargados de proveer una serie de bienes y servicios que los ciudadanos no podrían obtener del mercado. Con esa finalidad, deben llevar adelante una permanente tarea de redistribución y transferencia de recursos, fundamentalmente por vía impositiva, que les permita financiar esas prestaciones.

Esto suele acabar frustrándose. La aguda crisis de representatividad que afecta a los parlamentos actuales y a la administración en general, exige que la pretensión de certeza y previsibilidad que entraña el constitucionalismo, se traduzca en mecanismos jurídicos que eviten que los derechos sociales básicos se garanticen para todos.

${ }^{8}$ Vid. NOZICK, Robert, "Anarchy», State and Utopía, Oxford, 1974. Citado por: PISARELLO, G. «Los derechos sociales en el constitucionalismo democrático». Cuadernos electrónicos de filosofía del derecho, ISSN 1138-9877, n. ${ }^{\circ}$ 4, 2001 (Ejemplar dedicado a: Seminario «El contenido mínimo de los derechos sociales de los inmigrantes. Propuestas e indicadores de evaluación». (Valencia, 26 y 27 de noviembre de 2001). 
2. Los poderes privados, de mercado, dominan por su parte el ámbito en el que se genera gran parte de los recursos susceptibles de satisfacer las necesidades básicas de las personas. Para el constitucionalismo liberal clásico, este espacio económico resultaba intocable. Su protección exigía, de los poderes públicos, una actitud lo suficientemente firme como para mantener alejadas posibles intromisiones de terceros, a la propiedad y a la seguridad del tráfico. Por eso, los derechos fundamentales se configuraban verticalmente, frente al Estado, al tiempo que se cubría el derecho de propiedad con garantías reforzadas.

El constitucionalismo contemporáneo ha cambiado esta visión. Nace, por ejemplo, la problemática de la Drittwirkung, en virtud de la cual los derechos adquieren un sentido igualitario, y proyectan su sombra no sólo sobre los poderes públicos, sino también sobre los privados $^{9}$. En otras palabras, los derechos fundamentales ya no sólo se configuran verticalmente, frente al Estado, sino que extienden su fuerza obligatoria también horizontalmente, frente a terceros. Esto no significa, sin embargo, que todas las prestaciones sociales, constitucionalmente previstas, puedan exigirse directamente de los particulares.

\section{LA EXIGIBILIDAD JURÍDICA DE LOS DESC}

Trazaremos un breve recorrido por algunos textos jurídicos que recogen elementos de exigibilidad de los DESC.

\section{III.1. En la Constitución española}

Trataremos de centrar la cuestión en España, aunque la mayor parte de nuestro texto es aplicable a cualquier realidad jurídica en el contexto internacional.

Como han recordado algunos autores ${ }^{10}$, «la progresiva consagración de los derechos como auténticos derechos constitucionales sólo se ha perfeccionado, cuando así ha sido, respecto de los derechos más vinculados a los ámbitos civil y político. Los derechos de los

${ }^{9}$ Vid. VEGA, Pedro de, «La crisis de los derechos fundamentales en el Estado social», Derecho y economía en el Estado social, Madrid, Tecnos, 1988, págs. 130-135.

${ }^{10}$ José Ignacio MARÍNEZ ESTAY. Los derechos sociales en la Constitución española de 1978. Jurisprudencia constitucional española sobre derechos sociales , Sumario (2008). Universidad de Santiago de Compostela. Págs. 93-170. 
ámbitos económicos, social y cultural, salvo excepciones como el derecho a la educación (en algunos textos y con matices), aunque formalmente incorporados al corpus constitucional, a menudo han sido vaciados de garantías, hasta el punto de llegar a perder la propia esencia constitucional, esto es, su especial capacidad de resistencia frente a la actuación de poderes públicos y privados, incluida la propia Asamblea Legislativa. Esta capacidad de resistencia constitucional, obviamente, debe alcanzar la posibilidad de acceder a órganos judiciales independientes cuando cualquiera de los sujetos obligados, públicos o privados, incurre en vulneración de derechos, ya sea por acción o por omisión.

Pues bien, la mayor parte de textos constitucionales (a partir de la interpretación que de los mismos se ha acabado imponiendo) han desdibujado hasta hacer irreconocible la dimensión constitucional que debería referirse a todos los derechos por igual.

La Constitución española de 1978 es tributaria, en parte, de tales pautas. Inmersa su aprobación en el contexto de la crisis del constitucionalismo social, el texto finalmente aprobado en 1978 conjuga compromiso social con elementos propios del, entonces incipiente, desahucio neoliberal de un modelo social que se había llegado a desarrollar con cierto éxito en algunos países de la Europa occidental de posguerra. Así es, los trazos sociales como la cláusula de igualación material del artículo 9.2, la delimitación del derecho de propiedad por su «función social» (artículo 33) o las habilitaciones para la intervención estatal en el proceso económico contenidas en el título VII (artículos 128 y siguientes), se alternan con la centralidad de la libertad de empresa en el marco de la economía de mercado (artículo 38), el reconocimiento del derecho de los empresarios de adoptar medidas de conflicto colectivo (artículo 37) o la escasa presencia de las formas de democracia participativa.

El contexto recién descrito, ya bien se puede hoy afirmar, ha convertido a la norma constitucional en el marco jurídico-político de la transición hacia un Estado post-social (o pre-social, según se mire), a partir, además, de pactos de naturaleza política en cierta medida metaconstitucionales, como los Pactos de la Moncloa de 1977 o los Pactos de Convergencia europea en el marco de la firma del Tratado de Maastricht de 1992.

El reconocimiento constitucional de los derechos sociales atestigua hasta qué punto el texto constitucional de 1978 se mueve entre los polos de tensión descritos, situación que ha dado pie a diversas y encontradas interpretaciones de las previsiones constitucionales. La 
Constitución de 1978 sitúa a buena parte de los derechos sociales, exceptuando el derecho a la educación, en un capítulo específico (capítulo III dentro del Título I), bajo el título de «Principios Rectores de la Política Económica y Social». El primer factor de tensión aparece porque entre tales "principios rectores» se consagran mandatos a los poderes públicos, pero también derechos subjetivos como, y así se recoge literalmente, el "derecho" a una vivienda digna y adecuada (artículo 47), el «derecho» a la protección de la salud (artículo 43), el «derecho» de acceso a la cultura (artículo 44), o el «derecho» a disfrutar de un medioambiente adecuado (artículo 45).

La separación en distintos capítulos tiene propósitos jurídicos y no meramente sistemáticos: según los dos primeros apartados del artículo 53, encargado del sistema de garantías, los derechos del capítulo II, fundamentalmente derechos civiles y políticos, gozarán de garantías legales como la reserva de ley y el contenido esencial, y de garantías jurisdiccionales directas ordinarias, además de las especiales para el caso de los derechos de la sección primera del capítulo II (recurso preferente y sumario en sede ordinaria y recurso de amparo constitucional).

En cambio, el artículo 53.3 establece que «el reconocimiento, el respeto y la protección de los principios reconocidos en el Capítulo tercero informará la legislación positiva, la práctica judicial y la actuación de los poderes públicos. Sólo podrán ser alegados ante la Jurisdicción ordinaria de acuerdo con lo que dispongan las leyes que los desarrollen». Con ello, parece que los principios contenidos en el capítulo III operarían fundamentalmente como principios objetivos o como simples mandatos de optimización. Y así sucedería también con los «derechos» consagrados en dicho capítulo que, en contraste con los derechos del capítulo II, serían derechos de configuración legal, esto es, solamente alegables como derechos subjetivos ante los órganos jurisdiccionales si previamente han sido desarrollados por el legislador.

Frente a la devaluación de los derechos sociales y las razones esgrimidas por el discurso dominante, han surgido voces críticas que, al margen de apuntar la necesidad de cambios constitucionales, han sabido avanzar en formas de exigibilidad, acogidas en algunos pronunciamientos jurisprudenciales, y en una fundamentación teórica que pone de manifiesto el carácter en buena medida prejuicioso y político de los pretendidos motivos técnicos o estructurales que aconsejarían mantener la división, jerárquica al fin, entre derechos civiles y políticos, de un lado, y derechos sociales, económicos, culturales y ambientales, por otro». 


\section{III.2. En el derecho internacional de los derechos humanos}

Los estándares internacionales de derechos humanos cumplen un papel fundamental en el impulso de la exigibilidad de los derechos sociales a nivel interno de los Estados ${ }^{11}$. Esta interacción entre derecho internacional y derecho interno ha sido progresiva y se ha manifestado de diversas formas en las últimas décadas, según los diseños institucionales y legales propios de cada país.

Existen no sólo instrumentos internacionales de derechos humanos sino también jurisprudencia y decisiones (recomendaciones, resoluciones, observaciones generales, informes, etc.) de órganos de control de los sistemas internacionales de protección. Estos pronunciamientos que aún no han sido recogidos en tratados internacionales o en decisiones de organismos estrictamente judiciales, han sido reconocidos como doctrina autorizada o derecho emergente en la materia, también asociado al concepto de soft law: "Se trata de declaraciones o principios elaborados por importantes doctrinantes o por cuerpos especializados, que adquieren un valor jurídico importante, debido a que son adoptados por órganos internacionales, como la Asamblea General de Naciones Unidas, o al reconocimiento mismo que van ganando, en la medida en que son considerados expresiones de principios generales de derecho o de derecho internacional consuetudinario, o doctrina autorizada sobre el alcance de tratados específicos».

Las disposiciones que no son tratados carecen, en principio, de carácter vinculante u obligatorio (con excepción de la Declaración Americana y la Declaración Universal de Derechos Humanos). Sin perjuicio de ello, «la expresión soft law busca describir la existencia de fenómenos jurídicos caracterizados por carecer de fuerza vinculantes aunque no carentes de efectos jurídicos». En efecto, estas disposiciones sí adquieren valor jurídico al constituirse en una fuente complementaria para la adscripción de sentido a las normas obligatorias. En todo caso una norma de estas características deberá considerarse como doctrina autorizada, sin perjuicio de que por su observancia constante adquiera la naturaleza de costumbre o que detente valor jurisprudencial por ser acogida por los tribunales.

Estos estándares internacionales hacen parte de la doctrina autorizada de interpretación de las normas de derechos humanos.

${ }^{11}$ INSTITUTO INTERAMERICANO DE DERECHOS HUMANOS. «Protección internacional de los derechos económicos, sociales y culturales». 2008, pág. 43. 
Esta interpretación autorizada, a la luz del principio de interpretación más favorable a la persona humana, debe ser respetada por los Estados según el principio de buena fe en el cumplimiento de los tratados.

En este sentido, la Corte Interamericana ha dicho que:

[El] corpus juris del Derecho Internacional de los Derechos Humanos está formado por un conjunto de instrumentos internacionales de contenido y efectos jurídicos variados (tratados, convenios, resoluciones $y$ declaraciones). Su evolución dinámica ha ejercido un impacto positivo en el Derecho Internacional, en el sentido de afirmar y desarrollar la aptitud de este último para regular las relaciones entre los Estados y los seres humanos bajo sus respectivas jurisdicciones. Por lo tanto, esta Corte debe adoptar un criterio adecuado para considerar la cuestión sujeta a examen en el marco de la evolución de los derechos fundamentales de la persona humana en el derecho internacional contemporáneo (Opinión Consultiva OC-16, párr. 16).

En el ámbito español, existe una doctrina minoritaria -pero muy interesante- que se muestra partidaria de estas tesis defendidas por la Corte Interamericana.

GOMEZ ISA, F., por ejemplo, establece que «se necesitan mucha mayor reflexión y sinergias entre el ámbito académico, de la práctica judicial y de los gobiernos. Mientras existe un consenso emergente acerca del estatus jurídico y contenido del deber internacional de respetar $^{12}$ los derechos económicos, sociales y culturales, es más difícil afirmar la existencia de la obligación de realizar, especialmente en la dimensión de "proveer» ${ }^{13}$.

Las obligaciones de satisfacer o realizar imponen al Estado deberes de facilitar, proveer y promover el disfrute de los derechos. Estas obligaciones se generan en aquellos casos en los que, por razones ajenas a la voluntad o posibilidades de los titulares de derechos, ese disfrute no existe o se encuentra limitado. En estas circunstancias, se espera que el Estado sea un agente proactivo, capaz de incrementar el acceso al disfrute de los DESC.

Por lo tanto, en estas obligaciones cobra central importancia la acción estatal dirigida a:

— identificar situaciones problemáticas;

${ }^{12}$ Respetar implicaría que las políticas que se llevan a cabo no interfieren con el contenido esencial de los derechos.

${ }^{13}$ OBLIGACIONES TRANSNACIONALES EN EL CAMPO DE LOS DERECHOS ECONÓMICOS, SOCIALES Y CULTURALES. Revista Electrónica de Estudios Internacionales. 2009, pág. 13. 
- brindar soluciones frente a esas situaciones; y

- crear las condiciones que permitan a los titulares de los derechos gestionar su propio acceso a los bienes o servicios necesarios disfrutar de esos derechos.

El deber de satisfacer los DESC incluye la obligación de eliminar obstáculos para el pleno disfrute de estos derechos. Esto requiere también la implementación de medidas para modificar patrones culturales y sociales de discriminación que resulten en una desventaja para grupos vulnerables.

\section{III.3. Las instituciones nacionales de derechos humanos: el papel del Defensor del Pueblo}

Existen muchos autores que defienden este papel del Ombudsman. Nos referimos a Maiorano ${ }^{14}$ y GrossEspiell ${ }^{15}$, entre otros.

Es posible que existan algunos problemas de exclusión de algunos temas o materias específicas del mandato de las instituciones nacionales. En algunos casos puntuales, se excluyen los derechos laborales. En otros casos -más comunes-, el mandato de las instituciones nacionales de derechos humanos se limita al control de las acciones u omisiones cometidas por el Estado o por agentes públicos, y excluye las cometidas por particulares ${ }^{16}$. Estas exclusiones pueden dejar de lado importantes violaciones de derechos sociales, en aquel universo de casos en los que estas violaciones correspondan a relaciones entre particulares. Estos casos no son extraños: derechos tales como los derechos laborales, el derecho a la salud, el derecho a la educación, el derecho a la vivienda o el derecho a la alimentación involucran frecuentemente vínculos entre particulares.

\footnotetext{
${ }^{14}$ Op. cit, p. 270.

15 «El Ombudsman. Su interés en la actual situación de Hispanoamérica». Revista de las Cortes Generales, Madrid, n. ${ }^{\circ}$ 4, 1985, pág. 204.

${ }^{16}$ Existen países que excluyen esta posibilidad, como España, en el artículo 1 de la LOTC. Ver, asimismo, Constitución Política de la República de Guatemala, artículos 274 y 275; Constitución Política de los Estados Unidos Mexicanos, artículo 102.B; Nicaragua, Ley de la Procuraduría para la Defensa de los Derechos Humanos, artículo 37. En contraste, existen en Centroamérica casos de reconocimiento explícito de la inclusión, dentro del mandato de las instituciones nacionales de derechos sociales, de actos $\mathrm{u}$ omisiones cometidos por particulares -por ejemplo, en materia de servicios públicos, independientemente del carácter del prestador. Es el caso de Costa Rica, Reglamento de la Ley de la Defensoría de los Habitantes de la República, artículo 2.';
} 
Esta tendencia se ha agudizado con el proceso de privatización de servicios públicos acaecida en muchos países de la región durante los años noventa, que puso en manos de prestadores privados o transfirió al sector privado de manera total o parcial la prestación de servicios públicos destinados a la satisfacción de derechos sociales -como la provisión de servicios de agua, de salud, de educación o la administración de la seguridad social. De modo que la exclusión de actos u omisiones de sujetos privados del mandato de las instituciones nacionales de derechos humanos puede tener el efecto de ignorar un universo importante de potenciales violaciones a derechos económicos, sociales y culturales.

Tales exclusiones, sin embargo, pueden ser parcialmente modificadas a través de algunas estrategias interpretativas -en la medida en que éstas tengan soporte normativo suficiente.

La primera es la aceptación de la aplicación de la prohibición de discriminación también a las relaciones entre particulares. De modo que, en principio, cabría la posibilidad de trabajar temas en los que la afectación de derechos económicos, sociales y culturales provenga de particulares, en aquellos casos en los que la situación pueda calificarse como violatoria de la prohibición de discriminación. Esta interpretación haría posible la competencia de las instituciones nacionales, por ejemplo, en casos de violación del derecho a la salud o a la educación por parte de prestadores de servicios de salud o establecimientos educativos privados, siempre que la situación denunciada incluya dimensiones de discriminación.

Una segunda estrategia para disminuir el posible efecto pernicioso de la exclusión de las relaciones entre particulares del mandato de las instituciones nacionales de derechos humanos es la «traducción» de una violación cometida entre sujetos privados en una violación imputable al Estado por falta de regulación, vigilancia o supervisión adecuada. Aunque es claro que esta forma de encuadrar la situación tiene desventajas, dado que el responsable directo de la violación es el sujeto privado y no el Estado, de todos modos puede ofrecer una salida práctica en los casos en los que no haya otra manera de salvar la exclusión. Algunos autores ${ }^{17}$ apuestan por esta solución en casos como los de violencia familiar, en que la causa de la misma puede entenderse que es la omisión del Estado, que no regula suficientemente la materia. El no prever sanciones por violencia de género, por ejemplo, facilita la violación de los derechos de la mujer.

${ }^{17}$ GUEDÁN, M.; IRÁIZOZ, M. Las Defensorías del Pueblo. Un puente entre la ciudadanía y el Estado en América Latina. Madrid, Ed. Trama, 2006. 
En todo caso, cabe recordar, que en materia de derechos humanos rige el denominado principio pro homine o pro persona, que prescribe que, en caso de duda interpretativa, o en caso de necesidad de elección entre dos normas, debe preferirse aquella que tenga por efecto el reconocimiento más extenso o la mayor protección de los derechos de la persona ${ }^{18}$.

Por tanto, en caso de duda razonable acerca del mandato de una institución nacional de derechos humanos, debe estarse a favor de aquella interpretación que permita incluir situaciones de presunta violación a los derechos humanos dentro de la competencia de la institución, y en contra de aquella que la excluya. Este debería ser el criterio que guíe la interpretación de los límites de sus propias facultades por parte de las instituciones nacionales de derechos humanos -al menos para ser coherentes con la propia razón de su existencia.

Conviene recordar que, en su informe de mayo de 2012, el Comité de derechos DESC estableció, refiriéndose al caso español:

"El Comité insta al Estado parte a que, en virtud del principio de indivisibilidad, universalidad e interdependencia de los derechos humanos, adopte las medidas legislativas pertinentes para garantizar a los derechos económicos, sociales y culturales un nivel de protección análogo que el que se aplica a los derechos civiles y políticos. Asimismo, el Comité recomienda al Estado parte que tome las medidas adecuadas para asegurar la plena justiciabilidad y aplicabilidad de todas las disposiciones del Pacto por los tribunales nacionales.»

Creemos que el Defensor del Pueblo español podría apoyar en esta tarea, aunque tiene claras restricciones en su mandato (artículo 9 de la Ley 3/1981 del Defensor del Pueblo), que no le permiten entrar a conocer de todos los derechos DESC.

${ }^{18}$ Ver S. ALBANESE, «La primacía de la cláusula más favorable a la persona», en Revista La Ley, Buenos Aires, tomo 1996-C-518; M. PINTO, «El principio pro homine. Criterios de hermenéutica y pautas para la regulación de los derechos humanos", en M. ABREGÚ y C. COURTIS (comps.), La aplicación de los tratados sobre derechos humanos por los tribunales locales, CELS-Editores del Puerto, Buenos Aires, 1997, págs. 163-171. Citados por: Christian Courtis. Cuadernos Electrónicos n. 5 Las instituciones nacionales de derechos humanos Derechos Humanos y Democracia. 


\section{III.4. Naciones Unidas}

El Comité de Derechos Económicos, Sociales y Culturales de Naciones Unidas ${ }^{19}$ destaca en su Observación General n. ${ }^{\circ} 10$ lo siguiente:

2. El Comité advierte que las instituciones nacionales desempeñan un papel que puede ser decisivo en la promoción y la garantía de la indivisibilidad y la interdependencia de todos los derechos humanos. Desgraciadamente, con demasiada frecuencia no se ha reconocido a la institución esa función, o ésta ha sido descuidada o considerada de baja prioridad por la institución. Es indispensable, pues, que se preste plena atención a los derechos económicos, sociales y culturales en todas las actividades pertinentes de esas instituciones ${ }^{20}$. La lista que sigue da una idea de los tipos de actividades que las instituciones nacionales pueden emprender (y en algunos casos ya han emprendido) en relación con estos derechos:

a) el fomento de programas de educación e información destinados a mejorar el conocimiento y la comprensión de los derechos económicos, sociales y culturales, tanto entre la población en general como en determinados grupos, por ejemplo en la administración pública, el poder judicial, el sector privado y el movimiento laboral;

b) el minucioso examen de las leyes y las disposiciones administrativas vigentes, así como de los proyectos de ley y otras propuestas, para cerciorarse de que son compatibles con los requisitos estipulados en el Pacto Internacional de Derechos Económicos, Sociales y Culturales;

${ }^{19} \mathrm{http} / / /$ www2.ohchr.org/english/bodies/cescr/comments.htm (consulta: 13 julio 2010)

${ }^{20}$ Esto no es así en la práctica. Un ejemplo lo ofrece la Procuradora para el Defensa de los derechos humanos en El Salvador en el año 2005, que se queja de la falta de implicación del Estado en la defensa de estos derechos en su Informe Especial presentado al Comité de Derechos Económicos, Sociales y Culturales de la Organización de las Naciones Unidas (ONU), sobre la aplicación del Pacto Internacional de Derechos Económicos, Sociales y Culturales en El Salvador (1995-2005): 247. Esta Procuraduría lamenta, sin embargo, que no se haya transitado en El Salvador hacia la aplicabilidad y funcionalidad efectiva de tales instrumentos y mecanismos, al haberse continuado en la línea de disminuir las capacidades político-institucionales del Estado respecto a los derechos económicos, sociales y culturales, tanto al interior de sus fronteras nacionales como en relación a otros países e, incluso, respecto a diferentes actores económicos que, en el marco internacional, han cobrado especial relevancia para el respeto y garantía de estos derechos, sobre la base de afectar el ejercicio soberano de las funciones estatales. Todo lo cual ha propiciado graves reveses en materia de derechos fundamentales como el trabajo, la sindicalización, la seguridad social, la educación y la salud, en clara contravención al principio de progresividad que debería regir el desempeño estatal en estos ámbitos. 
c) la prestación de asesoramiento técnico o la realización de estudios en relación con los derechos económicos, sociales y culturales, inclusive a petición de las autoridades públicas o de otras instancias apropiadas;

d) la determinación de criterios nacionales de referencia que permitan medir el grado de cumplimiento de las obligaciones que impone el Pacto;

e) la realización de investigaciones $\boldsymbol{y}$ de estudios con vistas a determinar la medida en que se llevan a la práctica determinados derechos económicos, sociales y culturales, bien sea dentro del Estado en general, o en determinadas esferas o en relación con determinadas comunidades particularmente vulnerables;

f) la vigilancia de la observancia de derechos específicos que se reconocen en el Pacto y la preparación de informes al respecto dirigidos a las autoridades públicas y a la sociedad civil; y

g) el examen de las reclamaciones en que se aleguen violaciones de las normas aplicables en materia de derechos económicos, sociales y culturales dentro del Estado. 4. El Comité encarece a los Estados Partes que velen por que en los mandatos asignados a todas las instituciones nacionales de derechos humanos se preste una atención apropiada a los derechos económicos, sociales y culturales, y les pide que en los informes que presenten al Comité incluyan detalles tanto sobre los mandatos como sobre las principales actividades de esas instituciones.

Esta observación general del Comité, que como se sabe está dirigida a interpretar y apoyar la aplicación del Protocolo del Pacto Internacional de Derechos Económicos, Sociales y Culturales, reconoce la labor que las instituciones nacionales de derechos humanos -entre las que están los Procuradores y Defensores del Pueblo- tienen en relación a estos derechos. Se les insta a vigilar su observancia $\mathrm{y}$ a atender reclamaciones fundamentadas en los mismos.

Además, existen algunos mecanismos regionales e internacionales de protección a los DESC que contribuyen a hacer cumplir las obligaciones en el ámbito nacional y que contemplan la participación de la sociedad civil. Por ejemplo, el PIDESC cuenta con el ya mencionado Comité de Derechos Económicos, Sociales y Culturales de Naciones Unidas, que fue «el primer órgano creado mediante un tratado que proporcionó a las organizaciones no gubernamentales [ONG] la oportunidad de presentar declaraciones por escrito y oralmente sobre cuestiones relativas al disfrute o no disfrute de los derechos enunciados en el Pacto en un país concreto». La elaboración de un «Informe 
Alternativo» por parte de las ONG es una herramienta de exigibilidad social y política muy importante, ya que al presentarlos y cabildearlos ante el Comité pueden influir en las observaciones finales que este órgano dirige a cada Estado Parte del Pacto, en particular sus motivos de preocupación y recomendaciones específicas. Las visitas in situ y reportes de Relatores Especiales temáticos de la ONU también impulsan el cumplimiento de las obligaciones del Estado.

El sistema interamericano sí contempla un procedimiento por el que la Comisión y la Corte interamericanas de derechos humanos pueden conocer de violaciones a los DESC, reconocidos en la Convención Americana sobre Derechos Humanos o Pacto de San José y en el Protocolo Adicional a esta Convención en materia de DESC o Protocolo de San Salvador.

Por otro lado, hay que recordar que la aprobación en diciembre de 2008 del Protocolo Facultativo al Pacto de Derechos Económicos, Sociales y Culturales posibilita a los Estados Parte que lo ratifiquen el reconocimiento de la competencia del Comité de la ONU de DESC para recibir y evaluar comunicaciones referidas a violaciones de los DESC. Dichas comunicaciones pueden presentarse por parte de individuos o grupo de individuos, una vez agotados todos los recursos internos en el plazo de un año desde la vulneración del derecho.

\section{IMPLICACIONES DE LA EXIGIBILIDAD JURÍDICA. ALGUNOS EJEMPLOS DE JURISPRUDENCIA FAVORABLE A LA EXIGIBILIDAD DE LOS DERECHOS ECONÓMICOS, SOCIALES Y CULTURALES}

Se observa ultimamente una tendencia que consiste en la reivindicación de la efectividad de los derechos económicos, sociales y culturales ${ }^{21}$. Algunos autores ${ }^{22}$ reclaman un sistema de metas, elementos de referencia o indicadores que debe servir para detectar violaciones por incumplimiento. Este sistema debe estar orientado a medir si se cumplen los con-

${ }^{21}$ PISARELLO, G. Los derechos sociales y sus garantías: elementos para una reconstrucción. Trotta, Madrid, 2007, pág. 111; ABRAMOVICH, COURTIS, op. cit; PARRA VERA, O. «El sistema interamericano y el enfoque de derechos en las estrategias de desarrollo y erradicación de la pobreza. Algunas líneas de trabajo para las Defensorías del Pueblo». Cuadernos electrónicos $n .^{\circ}$ 5. Derechos Humanos y Democracia.

${ }^{22}$ CALVO GARCÍA, M. "La implementación y efectividad de los derechos económicos, sociales y culturales». Cuadernos Democracia y Derechos Humanos. Los derechos sociales como una exigencia de la justicia. Madrid, 2009, pág. 216. El sistema de indicadores lo propone la Comisión Interamericana de Derechos Humanos en materia de indicadores de progreso. Vid. PARRA VERA, O. op.cit, pág. 93. 
tenidos mínimos de las obligaciones y si se producen violaciones fijadas como tales en los esfuerzos interpretativos desarrollados por los organismos competentes en la supervisión y garantía de los derechos sociales -entre los que se encuentran, por ejemplo, los Defensores del Pueblo.

También se observa cómo cada vez más llegan a los tribunales asuntos reclamando esta efectividad de los DESC. Los casos que conciernen a las obligaciones de garantizar los DESC incluyen el acceso a la prestación de servicios y el control de la legislación y las regulaciones necesarias para proveer tales servicios. Aun cuando la legislación o regulaciones existan, éstas deben satisfacer los criterios de razonabilidad, carácter adecuado, igualdad y no discriminación. Los casos pueden incluir:

- omisiones totales o parciales;

- incumplimiento de los estándares sustantivos relativos a la calidad de los servicios;

- incumplimiento de los requisitos y estándares procedimentales necesarios para planificar, implementar o vigilar la prestación de servicios;

- asignación insuficiente de recursos;

- incumplimiento en la implementación de las obligaciones positivas establecidas legislativamente;

- ausencia de regulación y vigilancia de las partes privadas cuando los servicios públicos necesarios para el disfrute de DESC están subcontratados o privatizados;

- incumplimiento en la prestación de servicios o en el otorgamiento de beneficios a personas con derecho a recibirlos.

Puesto que las obligaciones de satisfacer requieren de la acción positiva del Estado, la mayoría de los casos que contienen violaciones alegadas a estas obligaciones de satisfacción constituyen omisiones del Estado.

Cuando se identifica una omisión, la solución suele traducirse en una orden de hacer (por ejemplo, la orden de legislar, de brindar tratamiento médico, de pagar lo debido o de poner en práctica una determinada política) ${ }^{23}$.

${ }^{23}$ En este apartado nos hemos basado en el documento: «Los tribunales y la exigibilidad legal de los derechos económicos, sociales y Culturales. Experiencias comparadas de justiciabilidad», de la Comisión Internacional del Juristas, 2010. 
El caso Grootboom ofrece un buen ejemplo de escrutinio judicial de conformidad con las obligaciones de satisfacción ${ }^{24}$. La Corte Constitucional de Sudáfrica consideró que la política de vivienda adoptada por el gobierno omitió tomar en cuenta la situación de algunos de los grupos más vulnerables de la sociedad, como el grupo de ocupantes irregulares que fue desalojado en este caso.

En el caso Autism-Europe vs Francia, decidido por el Comité Europeo de Derechos Sociales ${ }^{25}$, el Comité interpretó que las medidas adoptadas por el gobierno de Francia para proveer orientación, educación, y entrenamiento vocacional para personas con autismo, especialmente niños, fueron insuficientes y no cumplieron con las obligaciones derivadas de la Carta Social Europea Revisada.

En varios casos ocurridos estadounidenses, consistentes en demandas por incumplimiento de obligaciones legislativas fundadas en la ley estadounidense sobre educación para las personas con discapacidad (Individuals with Disabilities Education Act, IDEA), los tribunales decidieron que las autoridades educativas violaron las obligaciones de satisfacción requeridas por esa ley. Las autoridades fueron declaradas responsable de no cumplir con la obligación de proveer un plan educativo individualizado, diseñado a medida para satisfacer las necesidades específicas de niños con discapacidad, que luego les permitiera su inclusión en el sistema educativo regular.

De modo similar, la Corte Suprema de Israel decidió que el derecho a la educación para niños con discapacidad incluía el derecho a una educación gratuita, no sólo respecto a la educación especial, sino también a los establecimientos educativos integradores. En este caso, el gobierno fue compelido a reestructurar sus previsiones presupuestarias para cubrir esos servicios.

En el caso People's Union For Civil Liberties vs Union of India and others, la Corte Suprema de la India ${ }^{26}$ hizo exigibles obligaciones del Estado de satisfacer DESC.

Disponible on line: http://icj.concepto.ch/dwn/img_prd/Justiciability-ESP-ElecDist. pdf (7 nov.2012).

Vid, además, Mathew Craven, 'Assessment of the Progress on Adjudication of ESC Rights', in Squires, Langford and Thiele, Road to a Remedy (n. 72 above), Chapter 3. CHRGJ Working Paper No. 15, 2007.

${ }^{24}$ Corte Constitucional de Sudáfrica, Gobierno de la República de Sudáfrica y otros vs. Irene Grootboom y otros, 2001 (1) SA 46 (CC), 4 de octubre de 2000.

${ }^{25}$ Véase Comité Europeo de Derechos Sociales, International Association AutismEurope vs Francia, Queja n. ${ }^{\circ}$ 1/2002, 7 de noviembre, 2003.

${ }^{26}$ Véase Corte Suprema de la India, People's Union For Civil Liberties vs Union of India y otros, 2 de mayo de 2003. 
Durante una hambruna en el estado de Rajasthán, muchas personas murieron de inanición, aún cuando el gobierno contaba con reservas de granos para situaciones de emergencias. A través de una serie de medidas cautelares, la Corte Suprema consideró que el gobierno no había implementado adecuadamente planes para prevenir y combatir la hambruna, y ordenó medidas urgentes de gran detalle para resolver la situación ${ }^{27}$.

En muchas jurisdicciones, son frecuentes las órdenes judiciales que obligan a autoridades públicas a actuar en conflictos relacionados con los servicios de salud, tanto en casos de individuales como colectivos. Los tribunales de América Latina han sido muy activos en este campo. La Corte Suprema argentina, por ejemplo, ha decidido en favor de un reclamo colectivo presentado por varias ONGs que defendían los derechos de las personas con VIH. La Corte ordenó al Ministerio de Salud proveer toda la medicación para el VIH requerida por la ley a los hospitales públicos.

Un número considerable de casos en la misma jurisdicción está constituido por demandas individuales en las que se reclama el acceso a tratamiento médico y a medicación. La Corte ha citado, en dos casos importantes, los tratados internacionales de derechos humanos, que imponen al Estado obligaciones positivas de proveer el acceso al tratamiento médico, y dio a la Administración órdenes de cumplir esas obligaciones. La Corte ha ordenado también la entrega de medicación a través de medidas cautelares.

La Corte Constitucional de Colombia ${ }^{28}$ ha seguido un camino similar, y ha decidido literalmente cientos de casos, en los que se conce-

${ }^{27}$ Entre ellas, se requiere al Gobierno que:

— implemente el Código Frente a Situaciones de Hambruna por tres meses;

- duplique la distribución de granos destinada al plan alimentario para trabajadores y que aumente la ayuda financiera para otros programas de alimentación;

- asegure que los programas de entrega de raciones de alimento estén disponibles y provean granos a las familias que se encuentran por debajo de la línea de pobreza al menor precio, y que efectúe campañas de difusión de los derechos de las familias pobres a obtener granos;

- entregue a todas las personas sin medios de supervivencia una tarjeta de racionamiento para obtener alimentos gratuitamente y que implemente progresivamente programas alimentarios en las escuelas.

${ }^{28}$ El número de casos resueltos por la Corte Constitucional de Colombia es notable. Véanse por ejemplo, las sentencias T-067/94, T-068/94, T-204/94, T-571/94, $T-020 / 95, T-049 / 95, T-179 / 00, T-1034 / 01$ y $T-1101 / 03$ (provisión de tratamiento y medicinas en casos en los que la salud de los niños con discapacidad está en riesgo); $T-533 / 1992$ (acceso a tratamiento gratuito para personas indigentes); T-179/1993 (garantía del derecho a la salud para mujeres embarazadas); T-153/1998, T-535/1998, T-606/1998, T-607/1998, T-530/1999, T-575/1999. 
dieron medidas cautelares y se ordenó a la agencia de seguridad social que suministrara los medicamentos y/o el tratamiento requerido.

En Brasil, también es común que se ordene judicialmente la provisión de medicinas y de tratamiento.

La Sala Constitucional de la Corte Suprema de Costa Rica, en muchos casos, ha ordenado a las autoridades públicas a suministrar el tratamiento médico en tiempo oportuno. Asimismo, la Corte Suprema de Venezuela dictaminó en una demanda colectiva que el Estado debía proporcionar antiretrovirales a 170 personas con VIH.

Existen muchos otros casos relacionados con la exigibilidad de estos derechos ${ }^{29}$. Uno de los primeros puede localizarse en Estados Unidos, y es el caso Goldberg v. Kelly, en que en 1971 se afirmó que el derecho a un debido proceso podría ser invocado por un solicitante cuyos sus beneficios sociales se habían terminado sin notificación. which affirmed that the right to procedural due process could be invoked by an applicant whose social security benefits had been 74 This notion of the various obligations endangered by rights was first pinpointed by Henry Shue in Basic Rights:

En el caso Social and Economic Rights Action y Center for Economic and Social Rights vs Nigeria (SERAC y CESR), la Comisión Africana de los Derechos Humanos y de los Pueblos aplicó la noción de obligaciones de respeto del goce de los DESC.

La Comisión afirmó que:

"La obligación de respetar implica que el Estado debe abstenerse de interferir en el goce de todos los derechos fundamentales; debe respetar a los titulares del derecho, sus libertades, su autonomía, sus recursos, y su libertad de acción.

Con respecto a los derechos socio-económicos, esto significa que el Estado está obligado a respetar el libre uso de los recursos propios o que están a disposición del individuo para sí o para cualquier grupo con el que se encuentre asociado, incluido su hogar, para satisfacer necesidades relativas a estos derechos.

$Y$ en relación con una comunidad, los recursos que le pertenecen deben ser respetados, pues estos mismos recursos deben emplearse para satisfacer sus necesidades.»

La Comisión interpretó que el gobierno de Nigeria no cumplió con sus obligaciones de respetar los derechos a la salud y a un medio

${ }^{29}$ Aoife NOLAN, Bruce PORTER, Malcolm LANGFORD. Center for human rights and global justice working paper. number 15, 2007. «The justiciability of social and economic rights: an updated appraisal». 
ambiente sano. La Comisión también consideró que se había violado el derecho a la vivienda:

"Como mínimo, el derecho a tener acceso a un albergue obliga al gobierno nigeriano a no destruir las viviendas de sus ciudadanos y a no obstruir los esfuerzos de individuos o comunidades de reconstruir sus casas perdidas. La obligación del Estado de respetar el derecho a la vivienda lo requiere, y por esta razón, todos su órganos y agentes deben abstenerse de llevar a cabo, patrocinar o tolerar cualquier práctica, política o medida legal que viole la integridad del individuo o infrinja su libertad de usar aquellos materiales u otros recursos disponibles de la forma que estimen más apropiada para satisfacer sus necesidades de vivienda individual, familiar, grupal o comunitaria. [...] El gobierno ha destruido las casas y poblados de la comunidad Ogoni y luego, a través de sus fuerzas de seguridad, ha obstruido, acosado, golpeado y, en algunos casos, disparado y asesinado a ciudadanos inocentes que trataron de reconstruir sus casas destruidas. Esas acciones constituyen masivas violaciones del derecho a la vivienda, por violar los Artículos 14, 16, y 18(1) de la Carta Africana.»

Además de las normas constitucionales de los países, los tribunales utilizan en sus sentencias sobre derechos DESC algunos tratados internacionales, la doctrina de Naciones Unidas contenida en sus Observaciones Generales y algunos otros textos como las Directrices de Maastricht ${ }^{30}$.

Estas directrices aportan elementos muy valiosos para justificar la exigibilidad en el ámbito judicial de los DESC. Así, se refieren a unas obligaciones básicas y fundamentales de todo Estado con respecto a los derechos, a las que no puede oponerse el argumento de falta de recursos económicos. Además, las Directrices de Maastricht se refieren a la obligación de proteger de los Estados en lo que se refiere a evitar que las empresas transnacionales vulneren derechos DESC.

Como conclusión, podemos decir que el tema que abordamos aquí necesita mucho estudio y profundización. Existe una corriente jurídica demasiado importante que niega la exigibilidad de los DESC ante los tribunales. Hemos aportado algunos argumentos a favor, e incluso, algunos ejemplos del iniciativas favorables -provenientes de diferentes órganos jurisdiccionales o no. Pero se necesita mayor trabajo a favor de esta cuestión: trabajo a nivel doctrinal, legal, judicial, extrajudicial, tanto en el nivel nacional como internacional, en el plano teórico y en el práctico.

${ }^{30}$ Maastricht Guidelines on Violations of Economic, Social and Cultural Rights, Maastricht, January 22-26, 1997, publicadas en Human Rights Quarterly, Vol. 20 (1998), págs. 691-705. 